\title{
Thermodynamic Study of Liquid Zn-Pb Alloys*
}

\author{
Zensaku Kozuka**, Yoichi Nakai** and Joichiro Moriyama**
}

\begin{abstract}
Thermodynamic properties of liquid $\mathrm{Zn}-\mathrm{Pb}$ alloys above $1000^{\circ} \mathrm{C}$ and the vapor-liquid equilibrium composition of this system at one atmospheric pressure were determined by e.m.f. measurements. The cell used in this work was of the closed type made of quartz. Measurements were carried out over a temperature range of $850^{\circ}$ to $1050^{\circ} \mathrm{C}$. From these experimental results the liquid alloys were found to exhibit considerble positive deviations from Raoult's Law and an irregular behavior. From the results obtained by the present experiment and by other workers, the following equations were derived for $\ln \gamma$ as a function of temperature and alloy composition.

$\ln \gamma \mathrm{Zn}_{\mathrm{n}}=\left(22000 / T^{1.35}\right)\left(1-N_{\mathrm{Zn}_{\mathrm{n}}}\right)^{1.48}$.

$\ln \gamma_{\mathrm{Pb}}=\left(22000 / T^{1.35}\right)\left[\left(1-N_{\mathrm{Zn}}\right)^{1.48}-3.08\left(1-N_{\mathrm{Zn}}\right)^{0.48}+2.08\right]$.

From these equations the vapor-liquid equilibrium of the $\mathrm{Zn}-\mathrm{Pb}$ system at one atmospheric pressure was determined, from which the ratio of $N_{\mathrm{Pb}}(\mathrm{g}) / N_{\mathrm{Pb}}(1)$ for the infinite dilute solution was known nearly equall to 0.012 . Furthermore it was confirmed that various values calculated from these equations were in good agreement with their reliable experimental data over a temperature range from $600^{\circ}$ to $1100^{\circ} \mathrm{C}$.
\end{abstract}

(Received September 14, 1964)

\section{Introduction}

Thermodynamic properties of liquid $\mathrm{Zn}-\mathrm{Pb}$ alloys have so far been studied by many investigators ${ }^{(1)}$, because the behavior of lead in zinc is very important for zinc smelting and refining processes. The present authors studied the binary system at $450 \sim 650^{\circ} \mathrm{C}$ by means of e.m.f. measurements, the results of which were reported in a previous paper ${ }^{(2)}$. Lumsden ${ }^{(3)}$ and Krupkowski ${ }^{(4)}$ proposed characteristic equations in which the activity coefficients of components were represented as a function of temperature and composition, the former was by a statistical method and the latter by an equilibrium phase diagram.

However, all these investigations were carried out at temperatures lower than $900^{\circ} \mathrm{C}$, so that the present experiment was carried out at $850 \sim 1050^{\circ} \mathrm{C}$ by means of e.m.f. measurements with a specially devised galvanic cell in order to investigate the thermodynamic properties of this binary solution at higher temperatures.

* This paper was pablished in Japanese in the Journal of the Japan Institute of Metals, 28(1964), 407.

** Department of Metallurgy, Faculty of Engineering, Kyoto University, Kyoto, Japan.

(1) O. J. Kleppa : J. Amer. Chem. Soc., 74(1952),6052 ; F. D. Rosenthal, G. J. Mills and F. J. Dunkerley : Trans. AIME, 212 (1958), 153.

(2) Z. Kozuka, J. Moriyama and I. Kushima: J. Electrochem. Soc. Japan, 30 (1962), 663.

(3) J. Lumsden: Thermodynamics of Alloys, London (1952)

(4) A. Krupkowski : Freiberger Forschungshefte, B 67 (1962), 101.

\section{Experimental Methods}

In this investigation, e.m.f. measurements were made on the galvanic cells of $\mathrm{Zn}$ (liq.) $/ \mathrm{Zn}^{++} / \mathrm{Zn}$ - $\mathrm{Pb}$ alloys(liq.). The cell used was of a closed type similar to that introduced by Wynnemer and Prockshot ${ }^{(5)}$, constructed of transparent quartz as shown in Fig. 1. Tungsten wires were used as lead wires, which were sealed with quartz by using molybdenum foils.

The part D in Fig. 1 was also sealed in vacuum to prevent oxidation of the tungsten lead wires. The four electrode parts consisted of one pure zinc and three alloy electrodes and were conected with the by-pass $G$. The purity of the metals used for this experiments was higher than $99.99 \%$ and the alloy electrodes were prepared by melting after granules of the component metals were sufficiently mixed. It was found by the preliminary expriment that the gravity segregation would not occur in the alloy melts thus produced. The salts used as electrolytes were composed of a potassium chloridesodium chloride eutectic mixture and $5 \%$ zinc chloride, and these salts were used after prefusion in dry hydrogen chloride atmosphere. The experimental method was as follows : After salts used as electrolytes and metallic specimens were charged in each electrode part as shown in Fig. 1 (II), they were sealed at the part shown by $\mathrm{A}$ and the cells were connected with the vacuum system. After the salts and metallic materials were degassed for

(5) D. J. Wynnemer and G.W. Preckshot: Trans. AIME, 221 (1961), 186. 
about $10 \mathrm{hr}$ at $200^{\circ} \mathrm{C}$, the cells were sealed at the part $\mathrm{C}$ and transferred to the furnace. The furnace used was of a nichrom resistance winding type and the furnace temperature was controlled automatically in the range of $\pm 1{ }^{\circ} \mathrm{C}$. The e.m.f. values were measured by means

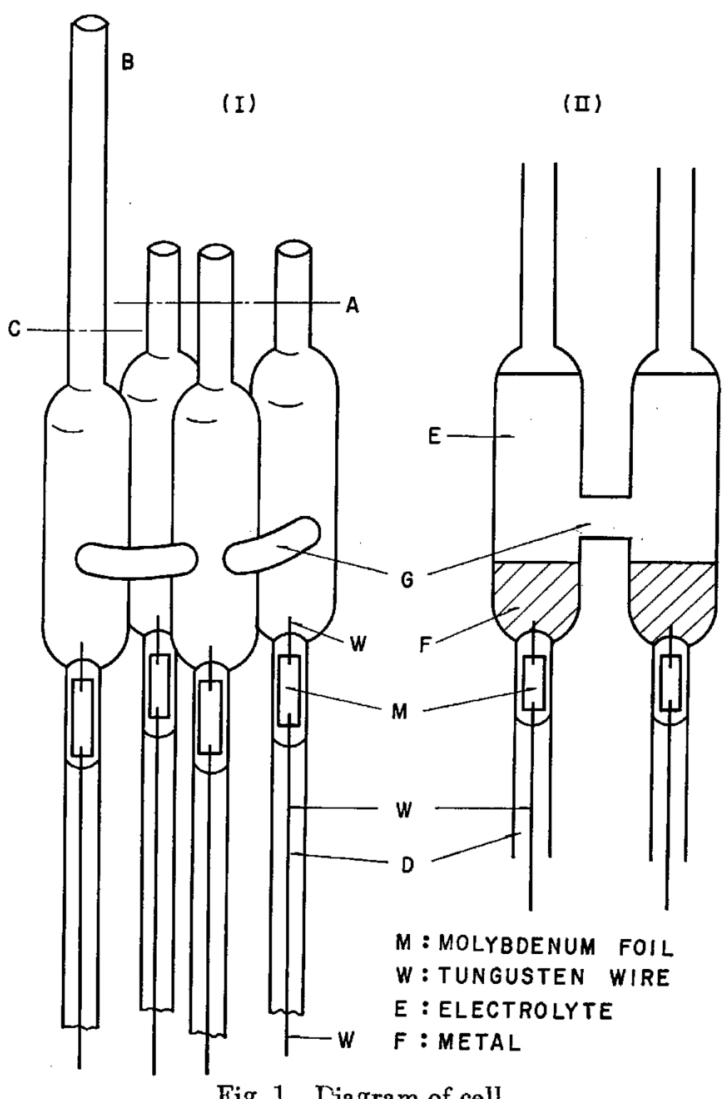

of a $\mathrm{K}-2$ potentiometer. The readings of e.m.f. remained unchanged within $\pm 0.05 \mathrm{mV}$ when an equilibrium was attained.

\section{Experimental Results}

The values of e.m.f. measured between pure zinc and six alloys of different compositions as a function of temperature are given in Fig. $2 . N_{\mathrm{Zn}}$ represents the atomic fraction of zinc in liquid alloys. It appeared that the plots against $N_{\mathrm{z}_{\mathrm{n}}}$ was about linear in the tempera-

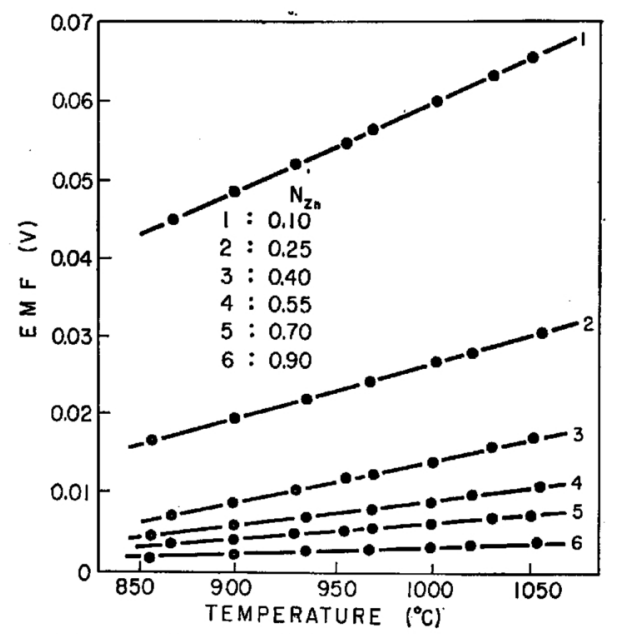

Fig. 2 Change of EMF with temperature. ture range from $850^{\circ}$ to $1050^{\circ} \mathrm{C}$. The values of e.m.f. at $1050^{\circ} \mathrm{C}$ and its temperature dependence $\Delta E / \Delta T$ are shown in Table 1. From these experimental results the activities of components at 900,970 , and $1050^{\circ} \mathrm{C}$ were calculated as shown in Fig. 3. The activities of

Table 1 Experimental results of liquid $\mathrm{Zn}-\mathrm{Pb}$ alloys at $1050^{\circ} \mathrm{C}$.

\begin{tabular}{|c|c|c|c|c|}
\hline $\begin{array}{c}\text { Sample } \\
\text { No. }\end{array}$ & $N_{\mathrm{Zn}}$ & $E\left(\right.$ at $\left.1050^{\circ} \mathrm{C}\right)$ & $\Delta E / \Delta T(V / \mathrm{deg})$ & $a_{\mathrm{Zn}}\left(\right.$ at $\left.1050^{\circ} \mathrm{C}\right)$ \\
\hline $\begin{array}{l}1 \\
2 \\
3 \\
4 \\
5 \\
6\end{array}$ & $\begin{array}{l}0.10 \\
0.25 \\
0.40 \\
0.55 \\
0.70 \\
0.90\end{array}$ & \begin{tabular}{|c|}
$65.38 \times 10^{-3}$ \\
$30.30 " \mathrm{\prime \prime}$ \\
$16.87 \mathrm{\prime \prime}$ \\
$10.85 \mathrm{\prime \prime}$ \\
$7.37 \mathrm{\prime \prime}$ \\
$3.72 \mathrm{\prime \prime}$
\end{tabular} & $\begin{array}{l}0.112 \times 10^{-3} \\
0.068 \mathrm{\prime \prime} \\
0.046 \mathrm{\prime \prime} \\
0.033 \mathrm{\prime \prime} \\
0.021 \mathrm{\prime \prime} \\
0.007 \mathrm{\prime \prime}\end{array}$ & $\begin{array}{l}0.314 \\
0.587 \\
0.743 \\
0.826 \\
0.878 \\
0.937\end{array}$ \\
\hline
\end{tabular}

zinc were calculated by the following equation.

$R T \ln a_{\mathrm{Zn}}=-n E F$.

$R$ : gas constant $T:$ absolute temperature $a_{\mathrm{Zn}}$ : activity of zinc $n:$ number of electrons participating in the reaction $E$ : electromotive force of the cell

Based on these activities of zinc, the activities of lead were calculated by the Gibbs-Duhem equation.

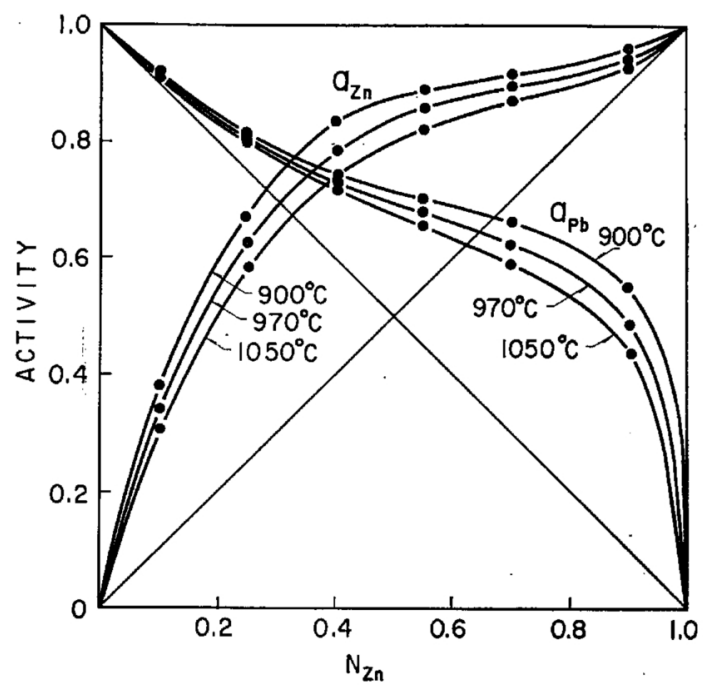

Fig. 3 The activities of both components in liquid $\mathrm{Zn}-\mathrm{Pb}$ alloys.

It was found that the liquid alloys exhibited considerable positive deviations from Raoult's Law. In addition, from the experimental results the following thermodynamic quantities of the liquid alloys at $970^{\circ} \mathrm{C}$ were calculated. The partial and total excess free energies $\Delta \bar{F}_{Z \mathrm{n}}^{x s}, \Delta \bar{F}_{\mathrm{Pb}}^{x s}, \Delta F^{x s}$ are shown in Fig. 4 , and heats of mixing $\Delta \bar{H}_{\mathrm{Zn}}, \Delta \bar{H}_{\mathrm{Pb}}, \Delta H$ in Fig. 5 and excess entropies $\Delta \bar{S}_{\mathrm{zn}}^{x s}$, $\Delta \bar{S}_{\mathrm{pb}}^{x s}, \Delta S^{x s}$ in Fig. 6. From these figures it was found that $\Delta F^{x s}$ exhibited the highest value, about $1.05 \mathrm{kcal} /$ mole, at the composition of $N_{\mathrm{z}}=0.55, \Delta H 1.3 \mathrm{kcal} /$ mole at $N_{\mathrm{zn}}=0.58$, and $\Delta S^{x s} 0.27 \mathrm{cal} / \mathrm{deg}$. mole at $N_{\mathrm{zn}}$ $=0.7$.

These values were not in agreement with those obtained by Predel et al.(6), presumably due to the temperature difference. The liquid alloys were found to exhibit slight deviations from the regular solution.

(6 ) B. Predel : Z. Phys. Chem. Neue Folge, 20(1959), 150. 
The vapor-liquid equilibrium relationship for the $\mathrm{Zn}-\mathrm{Pb}$ system at one-atmospheric pressure was made clear by the vapor pressure data for the two pure components and the activities of components. The vapor pressure of zinc and lead in the liquid $\mathrm{Zn}-\mathrm{Pb}$ alloys at certain tempera-

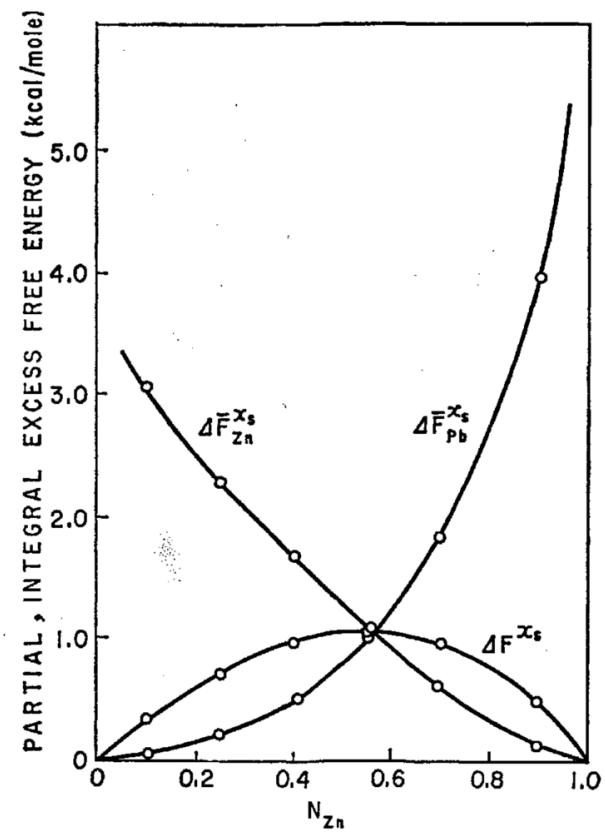

Fig. 4 Partial molal and integral excess free energy in liquid $\mathrm{Zn}-\mathrm{Pb}$ alloys at $970^{\circ} \mathrm{C}$.

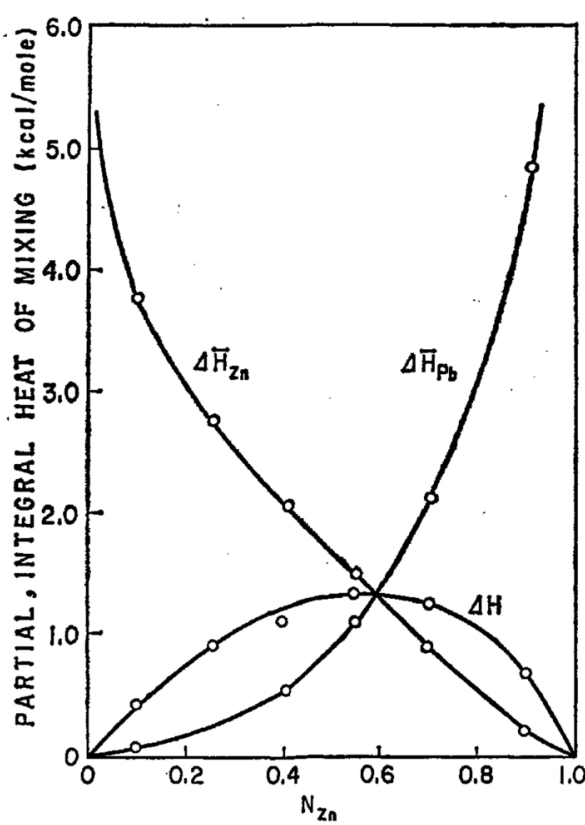

Fig. 5 Partial molal and integral heat of mixing in liquid $\mathrm{Zn}-\mathrm{Pb}$ alloys at $970^{\circ} \mathrm{C}$.

tures were given by :

$$
\begin{aligned}
& P_{i}=P_{i}^{\circ} \times a_{i}=P_{i}^{\circ} \times \gamma_{i \bullet} \\
& \log P_{i}=\log P_{i}^{\circ}+\log N_{i}+\log \gamma_{i} .
\end{aligned}
$$

$P_{i}$ : vapor pressure of component $i$ in the liquid alloys.

$P_{i}^{\circ}$ : vapor pressure of pure element $i$

$N_{i}$ : atomic fraction of component $i$

$a_{i}$ : activity of component $i$

$\gamma_{i}$ : activity coefficient of component $i$

If $\log P_{; n}^{\circ}$ will be given as a function of temperature and $\log \gamma_{z_{n}}$ as a function of temperature and alloy composition, $\log P_{\mathrm{z}_{\mathrm{n}}}$ may be expressed as a function of temperature and alloy composition.

The $\log P_{\mathrm{Pb}}$ may be similiary expressed as a function of temperature and alloy composition. The equations

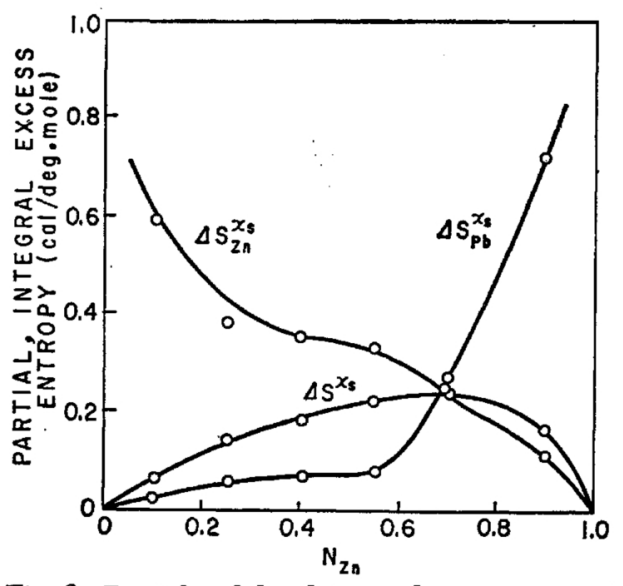

Fig. 6 Partial molal and integral excess entropy in liquid $\mathrm{Zn}-\mathrm{Pb}$ alloys at $970^{\circ} \mathrm{C}$.

for $\log P_{\gamma \mathrm{n}}^{\circ}$ and $\log P_{\mathrm{Pb}}^{\circ}$ were given by Kubaschewski ${ }^{(7)}$ as follows:

$$
\begin{aligned}
\log P_{\gamma_{\mathrm{n}}}^{\circ}= & -6620 / T-1.255 \log T \\
& +12.34(\mathrm{mmHg}) . \\
\log P_{\mathrm{Pb}}^{\circ}= & -10130 / T-0.985 \log T \\
& +11.16(\mathrm{mmHg}) .
\end{aligned}
$$

Based on the present experimental results, the following equations were derived for $\log \gamma_{\mathrm{Z}_{\mathrm{n}}}$ and $\log \gamma_{\mathrm{Pb}}$ as a function of temperature and alloy composition*.

$$
\begin{gathered}
\log \gamma_{\mathrm{Zn}_{\mathrm{n}}}=\left(9550 / T^{1.35}\right)\left(1-N_{\mathrm{Zn}}\right)^{1.48} \\
\log \gamma_{\mathrm{Pb}}=\left(9550 / T^{1.35}\right)\left[\left(1-N_{\mathrm{Zn}}\right)^{1.48}-3.08\right. \\
\left.\left(1-N_{\mathrm{Zn}_{\mathrm{n}}}\right)^{0.48}+2.08\right]
\end{gathered}
$$

Substituting Eqs. (4) (7) in Eqs. (2), (3),

$$
\begin{aligned}
\log P_{\mathrm{Z}_{\mathrm{n}}} & =-6620 / T-1.255 \log T+12.34 \\
& +\log N_{\mathrm{Zn}_{\mathrm{n}}}+\left(9550 / T^{1.35}\right)\left(1-N \mathrm{z}_{\mathrm{n}}\right)^{1.48} . \\
\log P_{\mathrm{Pb}} & =-10130 / T-0.985 \log T+11.16 \\
& +\log N_{\mathrm{Pb}}+\left(9550 / T^{1.35}\right)\left[\left(1-N_{\mathrm{zn}}\right)^{1.48}\right. \\
& \left.-3.08\left(1-N \mathrm{z}_{\mathrm{n}}\right)^{0.48}+2.08\right] .
\end{aligned}
$$

The boiling points of the $\mathrm{Zn}-\mathrm{Pb}$ alloy system at one atmospheric. pressure were obtained by using Fqs. (6) and (7), and the vapor-liquid equilibrium relationship was deduced by applying Dalton's Law to these vapor phase. Fig. 7 shows these relationships, and Fig. 8 shows the vapor-liquid equilibrium relationship expressed by ratios of $N_{\mathrm{Pb}}$ in both phases.

As shown in Fig. 7, the authors' data on boiling pointcomposition were almost in agreement with the experimental results by Leitgebel(8) and Lumsden ${ }^{(3)}$, Krupkowski(4) and Predel(6). However, strictly speaking, the authors' result was in better agreement with Leitge-

(7) O. Kubaschewski and E. L. L. Evans : Metallurgical Thermochemistry, (1958)

* On these equations a further explanation will be made in the following discussion.

(8) W. Leitgebel : Z. anorg. Chem., 202 (1931), 320. 
bel's and showed some discrepancy from Lumsden's.

For determining the vapor-liquid equilibrium relationship for the refining process of crude zinc, the relationship in the infinite dilute lead solution should be determined. Lumsden $^{(9)}$ proposed the relationship to be $N_{\mathrm{Pb}}(\mathrm{g}) / N_{\mathrm{Pb}}$

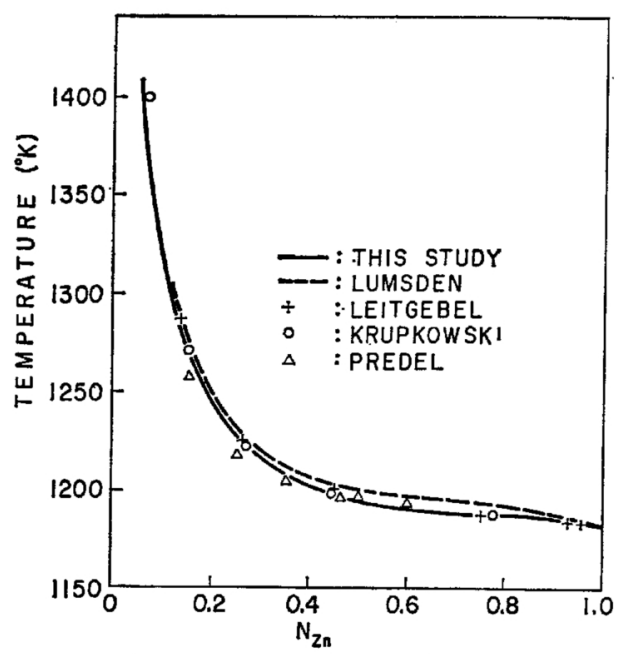

Fig. 7 Boiling points of $\mathrm{Zn}-\mathrm{Pb}$ alloys at atmospheric pressure.

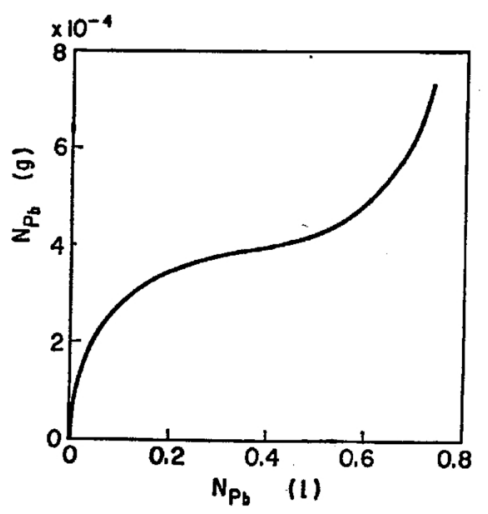

Fig. 8 Composition of the vapor from boiling $\mathrm{Zn}-\mathrm{Pb}$ alloys.

(1) $=0.0041$ where $N_{\mathrm{Pb}}(\mathrm{g})$ is the atomic fraction of lead in the vapor phase and $N_{\mathrm{Pb}}(1)$ is that of lead in the liquid phase.

In this study the ratio of $N_{\mathrm{Pb}}(\mathrm{g}) / N_{\mathrm{Pb}}$ (1) at the infinite dilute composition was calculated as follows : When the lead content in zinc is extremely small,

$N_{\mathrm{zn}} \fallingdotseq 1, T=1180^{\circ} \mathrm{K}$ and $P_{\mathrm{Zn}} \fallingdotseq P_{\mathrm{Zn}}^{\circ}$. Substituting this in $\mathrm{Eq}(7)$,

$\log \gamma_{\mathrm{Pb}}=6550 \times 2.08 / 1180^{1.35} \quad \therefore \gamma_{\mathrm{Pb}} \fallingdotseq 26$, using the relation $P_{\mathrm{Z}_{\mathrm{n}}} \fallingdotseq P^{\circ}$, ,

$$
\begin{array}{r}
N_{\mathrm{Pb}}(\mathrm{g}) / N_{\mathrm{Pb}}(1)=P_{\mathrm{Pb}} /\left(P_{\mathrm{Pb}}+P_{\mathrm{zn}_{\mathrm{n}}}\right) / N_{\mathrm{Pb}} \fallingdotseq P_{\mathrm{Pb}} / P_{\mathrm{z}_{\mathrm{n}}} / N_{\mathrm{Pb}} \\
=P_{\mathrm{Pb}}^{\circ} \times 26 / P_{\mathrm{zn}}^{\circ}=0.347 \times 26 / 760=0.012 .
\end{array}
$$

The result shows that the lead content in the gas phase is 0.012 times as large as that in the liquid and is not in good agreement with the ratio calculated by Lumsden.

\section{Discussion}

Based on the equilibrium diagram, Krupkowski deduced the following equations for $\ln \gamma$.

In $\gamma_{\mathrm{Z}_{\mathrm{n}}}=(2720 / T-0.800)\left(N_{\mathrm{Zn}}\right)^{1.48}$.

(9) J. Lumsden Discuss. Faraday Soc., 4(1948), 60.

$$
\begin{gathered}
\ln \gamma_{\mathrm{Pb}}=(2720 / T-0.800)\left[\left(1-N_{\mathrm{Zn}}\right)^{1.48}\right. \\
\left.-3.08\left(1-N_{\mathrm{Zn}}\right)^{0.48}+2.08\right] .
\end{gathered}
$$

Lumsden assumed a characteristic equation to represent the change in free energy when 1 g-atom of a liquid $\mathrm{Zn}$ $\mathrm{Pb}$ alloy is formed from its liquid components by means of a statistical mechanical method. Based on the equation, Krupkowski(4) deduced the following equations for ln $\gamma$.

$$
\begin{gathered}
\ln \gamma_{\mathrm{Zn}_{\mathrm{n}}}=(2898 / T-0.990)\left(1-N \mathrm{zn}_{\mathrm{n}}\right)^{1.473} . \\
\ln \gamma_{\mathrm{Pb}}=(2898 / T-0.990)\left[\left(1-\mathrm{N}_{\mathrm{zn}}\right)^{1.473}\right. \\
\left.-3.114\left(1-N_{\mathrm{Zn}_{\mathrm{n}}}\right)^{0.473}+2.114\right] .
\end{gathered}
$$

The present authors eventually used Eqs. (6), (7) to represent $\log \gamma$, but in order to compare the present experimental results with those mentioned above, the following equations were derived :

$$
\begin{aligned}
\ln \gamma_{\mathrm{zn}} & =(2464 / T-0.542)\left(1-N \mathrm{zn}^{1.48} .\right. \\
\ln \gamma_{\mathrm{Pb}} & =(2464 / T-0.542)\left[\left(1-N_{\mathrm{zn}}\right)^{1.48} .\right. \\
& \left.-3.08\left(1-N_{\mathrm{zn}_{\mathrm{n}}}\right)^{0.48}+2.08\right]
\end{aligned}
$$

The $\ln \gamma_{\mathrm{z}_{\mathrm{n}}}$ calculated by Eqs. (10), (12) and (14) are plotted in Fig. 9 as a function of $N_{\mathrm{Zn}}$ for $700^{\circ}$, $1000^{\circ}, 1173^{\circ}$ and $1323^{\circ} \mathrm{K}$.

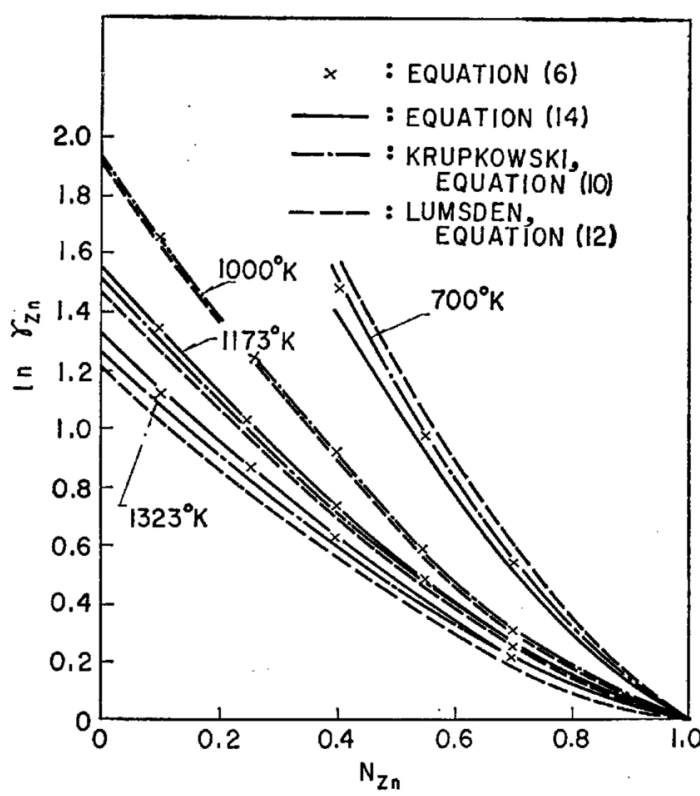

Fig. 9 Comparison of $\ln \gamma_{\mathrm{zn}}$ for liquid $\mathrm{Zn}-\mathrm{Pb}$ alloy calculated by the three different methods.

This figure shows that the values calculated by three different equations are in good agreement with one another at about $1000^{\circ} \mathrm{K}$, but with its deviation from this temperature, the values show an increasing difference.

Let us consider the coefficients $\alpha, \beta$ and $m$ in the equation $\ln \gamma_{\mathrm{z}_{\mathrm{n}}}=(\alpha / T-\beta)\left(1-N_{\mathrm{z}_{\mathrm{n}}}\right)^{m}$. The values of $m$ calculated by the three different equations were found to be 1.48 , and 1.473 which were in good agreement with one another, but the values $\alpha$ and $\beta$ showed some discrepancies by the equatiens. According to the following general relations, $\overline{\Delta H_{\mathrm{Z}_{\mathrm{n}}}}=-R T^{2}\left(\partial \ln \gamma_{\mathrm{Z}_{\mathrm{n}}} / \partial T\right), \overline{\Delta S_{Z_{\mathrm{n}}}^{x s}=}$ $R \ln \left(\gamma_{\mathrm{zn}}-R T\left(\partial \ln \gamma_{\mathrm{zn}} / \partial T\right)\right.$, Eqs. $\Delta \bar{H}_{\mathrm{zn}}=R \alpha\left(1-N_{\mathrm{z}_{\mathrm{n}}}\right)^{m}$, $\Delta \bar{S}_{\mathrm{Z}_{\mathrm{n}}}^{x s}=-R \beta\left(1-N_{\mathrm{Z}_{\mathrm{n}}}\right)^{m}$ can be derived. Therefore $\alpha$ and $\beta$ will be regarded as the coefficients dependent on $\Delta \bar{H}_{\mathrm{Zn}_{\mathrm{n}}}$ 


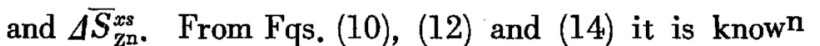
that both $\alpha$ and $\beta$ are nearly equal in Eqs. (10) and (12) and the coefficients in Eq. (14) are smaller than in the other equations. Since liquid $\mathrm{Zn}-\mathrm{Pb}$ alloys were not assumed to be a regular solution, $\Delta H$ and $\Delta S^{x s}$ of the liquid alloys would change with the temperature difference. Therefore, the discrepancies between the present experimental results and the other two results can be attributed to the difference in the temperature for measurement. As the equation $\ln \gamma_{\mathrm{Z}_{\mathrm{n}}}=(\alpha / T+\beta)\left(1-N_{\mathrm{Z}_{\mathrm{n}}}\right)^{m}$ is only applicable to a limited temperature range, Eqs. (6) and (7) were derived for their application in a wider temperature range. Let us consider the function $\ln \gamma_{\mathrm{z}_{\mathrm{n}}}=$ $\omega(T)\left(1-N_{\mathrm{Zn}_{\mathrm{n}}}\right)^{m}$ assuming $\omega(T)$ to be the characteristic function of its binary solution. The coefficient $m$ should be nearly 1.48 at any temperature so that the relation ship between the function $\ln \gamma_{\mathrm{z}_{\mathrm{n}}} /\left(1-N_{\mathrm{z}_{\mathrm{n}}}\right)^{1 \cdot 48}=\omega(T)$ and the absolute temperature $T$ must be investigated. $\log \omega$ $(T)$ which was plotted on the basis of the experimental results by the authors and some others as a function of $\log T$ shows a linear relationship so given in Fig. 10, erom which Eqs. (5) and (6) were derived. The calculatfd $\ln \gamma_{z_{n}}$ from Eq. (6) is shown in Fig. 9 with the $x$

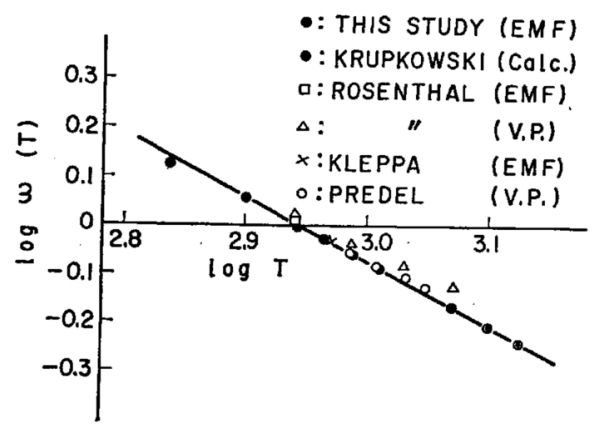

Fig. 10 Relation between $\log \omega(T)$ and $\log T$ of liquid $\mathrm{Zn}-\mathrm{Pb}$ alloys.

(V.P.): Vapor pressure measurement.

sign. It was found that these calculated values were in agreement with the authors' results at temperatures higher than $1000^{\circ} \mathrm{K}$ and with the results by Krupkowski and Lumsden at temperatures than $1000^{\circ} \mathrm{K}$. Furthermore, according to Krupkowski's literature ${ }^{(10)}$, the following problems will be discussed. With regard to $\Delta H$, the composition at which $\Delta H$ showed a maxium was calculated as follows :

$\log N_{\mathrm{Pb}}=-(\log m) /(m-1)=-\log 1.48 / 0.48 \therefore N_{\mathrm{Pb}}=$ 0.44 . Its maximum value was calculated according to the following relation.

$$
\Delta H=-R T^{2}\left\{\partial \omega(T\}\left\{N_{\mathrm{Pb}} /(m-1)\right\}\left(1-N_{\mathrm{Pb}}\right) .\right.
$$

The maximum heat of mixing was determined to be 1460 and $1610 \mathrm{cal} / \mathrm{mole}$ at $970^{\circ}$ and $600^{\circ} \mathrm{C}$ respectively in the composition of $N_{\mathrm{Zn}}=0.56$ and these values were in

(10) A. Krupkowski : Archiwum Huinicwa., 5(1960), 143. agreement with the results by the authors and Rosenthal(1)

The activitiy coefficient of zinc at the infinite dilute solution was calculated by a method shown in a previous report ${ }^{(11)}$. The value of $\gamma_{\mathrm{zn}}^{\mathrm{max}_{\mathrm{x}}}=10.3$ at $600^{\circ} \mathrm{C}$ thus derived was in good agreement with 11.0 that was obtained by the extrapolation of the most reliable Rosenthal's e.m.f. values. This demonstrates that Eqs. (6) and (7) may be used in the temperature range of $600 \sim 1000^{\circ} \mathrm{C}$. Furthermore, in order to determine the applicability of Eqs. (6) at a lower temperature, it must be investigated whether the monotectic composition calculated by the equation was nearly equal to other results as shown in previous papers by Lumsden ${ }^{(3)}$ and Krupkowski(4).

However, when consideration is given to the error in the standard free energy change for melting of the components it seems unreasonable to decide on the applicability of $\mathrm{Eq} .(6)$ at a lower temperature. The equation derived by Lumsden is very significant in using a statistical method, but it can only be applied to a limited range of temperatures, and in the dilute solution of lead there is a considerable discrepancy between experimental and calculated results. Eqs. (10) and (11) derived by means of the equlibrium phase relation proposed by Krupkowski can only be used in some limited range of temperatures. In contrast with these equations, Eqs. (6) and (7) are derived from the experimental and theoretical data over a wider temperature range, and they are confirmed to be in good agreement with the experimental results at $600^{\circ} \sim 1100^{\circ} \mathrm{C}$.

\section{Conclusion}

In order to determine the thermodynamic properties of liquid $\mathrm{Zn}-\mathrm{Pb}$ alloys at temperatures higher than $1000^{\circ}$ C, e.m.f. measurements were carried out at $850^{\circ} \sim$ $1050^{\circ} \mathrm{C}$. From these experimental results, it is known that the activities of both components exhibit a considerable positive deviation from Raoult's Law even at temperatures higher than $1000^{\circ} \mathrm{C}$, and its alloy solution has a slight deviation from the regular solution. On the basis of the experimental results by the authors and others over a wide temperature range the equations representing the activitiy coefficients of the components as a function of temperature and composition were determined. By using these equations the equilibrium relation of the vapor-liquid phase at one atmospheric pressure was deduced. These results was almost in agreement with the other experimental results in the previous literature. but a slight discrepancy between these results and the calculated ones reported by Lumsden was shown on the equilibrium relation at a dilute composition of lead.

(11) J. Moriyama, Z. Kozuka and H. Miura : Suiyokwaishi, 15 (1964), 191 . 